\title{
Aspects that Need to be Addressed During the Development of Location-Based Games
}

\author{
Jacques Barnard ${ }^{1}$, Magda Huisman ${ }^{1}$, and Günther Drevin ${ }^{1} \bowtie$ \\ School of Computer Science and Information Systems, \\ North-West University, \\ Potchefstroom, \\ South Africa \\ jacques. barnard1984@gmail.com, \\ magda.huisman@nwu.ac.za, \\ gunther.drevin@nwu.ac.za
}

\begin{abstract}
To determine the suitability of a software development methodology (SDM) to aid in the development of location-based games, it is necessary to determine to what degree SDMs address certain aspects that need to be addressed in the process of developing location-based games. These aspects will be identified based on information gathered in a literature review focused on aspects needed for a successful mobile application development process, game development process, as well as a mobile game development process. This is done to ensure that these aspects will better represent the needs of developing location-based games.

These aspects will be evaluated by using a survey to measure their importance in the development process and also to determine whether any aspects were overlooked.
\end{abstract}

Keywords: Software development methodologies, location-based games, game development

\section{Introduction}

The gaming industry is a rapidly expanding industry and is expected to reach 100 billion dollars worldwide by the year 2018. Furthermore, it is expected that the mobile gaming market will grow from 10 billion dollars in 2013 to 29 billion dollars in 2018 [15, 21].

The complexity of the development of games has increased exponentially [37] with one of the elements that contribute to this complexity being the multidisciplinary development process [8]. Different specialist areas, such as art, gameplay, sound, control systems, and human factors interacting with traditional software development all indicate that a specialised software engineering methodology is needed for this domain. Elements that lead to the complexity of game development are the technical challenges for the developers as well as tools, project size, workflow and other technical aspects [6]. 
This paper focuses on location-based games which is defined as a type of ubigame that focuses on the player's location and incorporates it in the game play [7]. This is to allow the player to be more immersed in the game world were the magic happens. Furthermore, location-based games are a type of mobile game and it is important to mention that the development of mobile games is just as complicated as console or on-line games [13]. This is due to the fact that the development of mobile games entails different aspects that are not included in the development of the other two previously mentioned game genres.

In this paper unique aspects that need to be addressed during the development process of location-based games are identified from the literature. These aspects are discussed in Section 2.

A survey is used to gather information from the gaming industry to determine the importance of each aspect and to determine whether the study has failed to identify any aspects. The survey process is discussed in Section 3 while the results are described in Section 4

\section{Aspects Identified from the Literature}

A list of 15 aspects, which are needed in the development process of locationbased games, were identified from literature that focuses on the development process of mobile applications, games and mobile games. Most of the identified aspects applies to game development projects in general, however some of the aspects are more applicable to location-based games. Each aspect will now be described in detail.

\subsection{Playability}

Playability can be defined as the property of an activity that has the ability to yield enjoyment [28]. This binary measure indicates whether or not a game can be enjoyed. This is one of the factors that determines the success of a game release. This is very important, as the main objective of any game is to provide the player with an enjoyable experience when playing the game. Playability leads to player experience, which is another aspect that will be discussed next [32]. Based on this it can be said that playability is a prerequisite for player experience. Playability is regarded to be very important to the game development process. The importance of playability can be further emphasised by indicating that there is a dedicated research area that focuses on playability heuristics $[10,26,27,32]$. This research focuses on determining issues with playability, as well as how to improve the playability of games. Furthermore, the research also mentions that usability alone is not enough in a game and that playability is also needed.

\subsection{Player Experience}

As mentioned previously, playability is a prerequisite for player experience. This prerequisite emphasises the tightly connected nature of these two aspects. The 
difference between the two aspects is that playability is the evaluative process of the player in respect of the game, whereas player experience is the evaluation of the players [32]. Player experience describes all sensorial experiences that a player experiences when playing a game [16]. Player experience can be compared with user experience in traditional information systems. The difference is that games are interactive systems with the main objective of exploiting the feelings of the player and ensuring fun and entertainment $[16,17]$. This difference enhances the complexity of player experience in a game compared to that of information systems $[16,31]$. However, it is insufficient to analyse the player experience by only using usability $[27,31]$. Usability, as well as playability are needed for the player experience to be fully incorporated in the game development. In the game design process player experience is an important focus and needs to be incorporated in the development of games [31].

\section{$2.3 \quad$ Usability}

Usability can be defined as the effectiveness, efficiency and user satisfaction in a specific context of use. Player experience benefits from incorporating usability in the game design process [31]. Furthermore, usability also affects playability [32]. By considering these two facts, it is clear that usability is important for game development. Another measure of the importance of usability is that the gaming industry is adopting formal techniques from human computer interaction [30]. These techniques are known as usability heuristics. Different usability heuristics to evaluate the usability of the game exist [17, 26, 30, 32]. However, only applying usability to the analysis of player experience is not sufficient due to the fact that games are more complex $[26,27]$ and applying these usability heuristics improves the design of games [30].

\subsection{Value to the Player}

Value to the player is also known as value to the user in the case of mobile applications. In this study, the term value to the player will be used. There are many mobile games that compete to be downloaded and played by players. An application or game is worthless if it does not add value to the player [43]. In other words, what makes a person choose a mobile game or application is the value that the game or application has for the person. This is done by utilising the functionality of the platform on which the mobile game or application is deployed, in this case a mobile device $[13,38]$. This functionality is valuable to the player if there is no other mobile game or application that can utilise the mobile device as the specific mobile game or application, thereby ensuring a unique gaming experience. Mobile applications or mobile games must also share their time with other activities conducted on the player's device, such as listening to music and instant messaging [13]. Another aspect that contributes to the value of the mobile game or application is incorporating the game or application into everyday life. Mobile games or applications that can increase productivity, help players perform day-to-day tasks, save time and relax players are some of the 
factors that can increase the value for the player [23,44]. Based on this, it is clear that value to the player is important and should be taken into account when developing a game.

\subsection{User Interface Design}

Location-based games are usually deployed on mobile devices as a location-based game is a mobile application. Knowledge about mobile applications with regard to user interface design is therefore also relevant for location-based games. The fact that location-based games are developed for hand-held devices allows the interface to be divided into three user interfaces (UIs), namely graphical user interface (GUI) [19,35], logical user interface (LUI) [19,42] and physical user interface (PUI). The GUI includes components that render the gaming world on the screen of the device. The LUI represents the logical flow of the mobile game. This can be navigation, player controls, menus and the use of gesture in the gaming world. The PUI is the physical medium that the player uses as input for the mobile game. This can be keyboard, touchscreen and different sensors, such as GPS, camera, accelerometer, etc. During the development of a location-based game, these UI elements need to be incorporated to improve the satisfaction of playing the game.

\subsection{Development Team}

The development team in a game company consists of different specialists $[3$, 9,33 . This adds complexity in managing the development process of games. Management needs to be able to create a balance between the needs of the different specialists, as well as the managerial tasks of the development team. The development process needs to take into account that different specialists need to work together on the same project. By addressing this aspect, the complexity of managing the development process can be reduced.

\subsection{Re-playability}

Re-playability can be defined as the quantifiable measure for the enjoyment that a player experiences while playing the game $[14,28]$. Re-playability also refers to the number of times a person can enjoy playing the specific game [28]. Re-playability can also be divided into different aspects, namely difficulty, completion, social aspects, randomisation and the experience [18]. The re-playability of games keeps players interested in the game until the release of either the next instalment of the game, or a game that is similar [14]. Due to the fact that most location-based games are restricted to a specific area in which they can be played, players can quickly become bored with the same game [18]. This is why it is important that the development process takes re-playability into account to allow players to replay the game as many times as possible without getting bored. 


\subsection{Learnability}

Learnability can be defined as a player's ability to understand and master the game $[34,39]$. Aspects that need to be understood and mastered can include the game's mechanics, objectives, rules and how to interact with the game. Learnability should also offer the player satisfaction in learning the game. It should also expand the player's knowledge and techniques to resolve challenges presented by new games. Learnability is one of the aspects that also influences the playability, as well as usability of a game. To focus on learnability as one of the aspects in the development process of games could enhance the playability and the usability of the game.

\subsection{Efficiency}

Efficiency is one of the measures that directly impacts usability. By this it can be said that usability incorporates efficiency [12]. Efficiency can be described as the player using the least amount of resources to achieve the goal of the game. This is also known as efficiency in user interaction. Furthermore, the efficiency of utilising hardware is also a crucial factor for mobile games, as resources on hand-held devices are limited [29]. For example, mobile games need graphics, sound and location-based services. For all these services the efficiency needs to be taken into account in the development of the game.

\subsection{Security and Privacy}

Security and privacy, although two very different concepts, are usually utilised in combination, as they are interdependent. Location-based games or services need to ensure that the location privacy of the players is secure [40]. If this is not done, the location or location history of the player can be made known to certain people $[36,40]$. When the players start to share, it does not mean that the players want to share all the information with everybody [40]. This is why it is important when developing a location-based game that privacy is kept in mind. The challenge of location-based games is in securing the privacy of the player without sacrificing the accuracy of the game [36]. This is why it is important that security aspects need to be included in the development process of a location-based game.

\subsection{Availability and Accessibility}

Mobile games, such as location-based games do not serve a purpose if they cannot be distributed to and utilised by players. Due to the rapid development and the shift that mobile technology has made to Android, Apple and Blackberry, the distribution and utilisation of mobile games have been simplified [20]. By creating centralised application or game portals, updates can be readily available, helping to reduce the management and support of these applications and games $[1,25,44]$. The effect that availability and accessibility have on developers, are 
that they need to incorporate and work towards publishing games and applications onto various markets to make it accessible to the public. These application markets make it possible for developers, with a level of ease, to make sure that applications and games are more available to the public [23]. For these reasons it is important to ensure that the development process of a location-based game incorporates availability and accessibility.

\subsection{Cognitive Support}

This aspect focuses on structuring the game's controls or input logically so that the player can play the game without uncertainty or excess effort [19]. It is important that players be able to predict the flow of operations when planning to perform a task on the game or application [23]. If the cognitive flow of an application or game is designed effectively, the user or player's chance of making a mistake decrease $[5,19]$. In addition, the cognitive process is the process a player carries out when executing a mobile phone task namely: planning, execution, translation and assessment [19]. A mobile game should also support these steps to decrease the effort of playing the game.

\subsection{Compatibility}

The rapid development in the mobile market has led to an increased in the different mobile devices and platforms [11,45]. This can result in complications for the development of location-based games, such as screen size, input device, control structures for sensor, etc. Because of these constraints, the development of any mobile application or game can be time consuming if a new project has to be developed for all platforms. Therefore, it is important that different techniques should be utilised for cross-platform development [2],[45]. The techniques that could aid in the development for different platforms are: using web application and application programming interfaces (APIs) that allow cross-platform development [11].

\subsection{Adaptability}

Adaptability can be described in two dimensions. The first is that the game should be adaptable to the context within which it is being used $[2,23,44]$. This can include making use of data, such as time, day, weather, GPS location and Internet connectivity. Secondly, the game should be able to adapt to the players' specifications, such as configuring display options, sounds, different sensor settings, difficulty settings, vibrations, etc. Lastly, location-based games usually focus on only one location for the game to be played [18]. If adaptability is incorporated in the development process, it may allow the location of the location-based game to be adaptable to the player's surroundings, adding another dimension to the location-based game. 


\subsection{Organisational Structure}

The organisational structure of a gaming company does not reflect the traditional structure of functional departments [9, 41]. Gaming companies resemble projectbased firms. Furthermore, if a gaming company is to be classified as a projectbased firm, the nature of the company exhibits specific aspects that are different from more traditional project-based firms. The complexity of managing a game project lies in the ability to maintain a balance between different specialists. Another complexity that is added to the development of game projects is that there needs to be a balance between artistic flexibility and strict managerial devices [41]. The development process needs to take this into account when a game is being developed.

\section{Survey}

The survey was in the form of a questionnaire with 15 questions, each of which was in the format "Rank the importance of ...". The responses were on a Likert scale from 1 to 10 where 1 was least important and 10 most important. The 15 questions were used to determine the rank of each of the 15 aspects identified from the literature, and discussed in Section 2.

In addition, the survey also had an open-ended question that allowed the respondents to add additional aspects if any were overlooked.

The survey was targeted at gaming companies, indie gamers and game development research labs and researchers. The response rate of the survey cannot be calculated accurately, as different forms of media were used to reach the respondents. The different types of media that were used to gather information via the survey were: email, an on-line survey, email groups and social media.

The first attempt at gathering information was done by attaching the questionnaire to an email that was then mailed to gaming companies and research labs. Using this approach, 15 completed questionnaires were gathered. However, the respondents indicated that it would be better to develop an online survey. This was done in Google Docs and emails were once again sent with the link to the questionnaire attached. The emails were sent to the developers that did not respond in the previous round. This resulted in a further 19 completed questionnaires. Next, the game research group gamesnetwork@listserv.uta.fi. was approached and a further 17 completed questionnaires were gathered.

After this the questionnaire was posted on gaming community groups on LinkedIn. These groups specifically cater for games developers and include: Android Game Development, design3, Games Developers, Games Developers Group, Game Development \& Design, Game Development Business, Gaming Passion and Profession, Mobile Game Development, The Online Game Group, Video Game Professionals and iPhone Android Mobile App Design, Development \& Promotion.

The last 27 responses to the questionnaires were gathered in this attempt. Through this iterative process, 78 completed questionnaires were collected during the survey. 
The results of the questionnaire will now be used to determine the importance of addressing each of the aspects during the development of location-based games.

\section{Results}

The results of the 78 completed questionnaires are shown in Table 1. Frequency analysis was also carried out on the data to show the frequency distribution of each question and the number of times each ranking occurs. This is shown in Table 2. In Table 1 the aspects have been arranged according to the average that each aspect scored in the survey. It is not surprising that playability ranked the highest amongst all the aspects according to mobile games developers and location-based games developers, as this is one of the most important aspects in games [32]. It is also interesting to see that the three aspects that are closely related, namely playability, user experience and usability scored the highest out of all the aspects. These results confirmed the findings in the literature that playability was more important than player experience, as playability is a prerequisite for player experience.

Table 1. Results of ranking aspects

\begin{tabular}{cccccc}
\hline & \multicolumn{7}{l}{ Average Median Minimum Maximum } & $\begin{array}{c}\text { Standard } \\
\text { Deviation }\end{array}$ \\
\hline Playability & 8.81 & 10 & 3 & 10 & 1.77 \\
Player Experience & 8.70 & 10 & 1 & 10 & 1.91 \\
Usability & 7.93 & 8 & 3 & 10 & 1.90 \\
Value to the Player & 7.67 & 8 & 1 & 10 & 2.44 \\
User Interface Design & 7.47 & 8 & 2 & 10 & 2.12 \\
Development Team & 7.37 & 8 & 1 & 10 & 2.32 \\
Re-playability & 7.34 & 8 & 1 & 10 & 2.47 \\
Learnability & 7.15 & 7 & 1 & 10 & 2.31 \\
Efficiency & 7.14 & 8 & 1 & 10 & 2.46 \\
Security and Privacy & 7.11 & 8 & 1 & 10 & 2.69 \\
Availability and Accessibility & 7.07 & 7 & 1 & 10 & 2.56 \\
Cognitive Support & 6.90 & 7 & 1 & 10 & 2.20 \\
Compatibility & 6.62 & 7 & 1 & 10 & 2.73 \\
Adaptability & 6.40 & 7 & 1 & 10 & 2.53 \\
Organisational Structure & 6.23 & 6 & 1 & 10 & 2.57 \\
\hline Average & $7.33^{*}$ & 8.00 & 1.33 & 10.00 & $2.44^{*}$ \\
& \multicolumn{5}{c}{$*$ Total value for entire dataset) } \\
\hline
\end{tabular}

The security and privacy aspect scored an average of 7.11 , which is lower than the average of 7.33 for all the aspects. From this it would seem that although security and privacy is important to the developers it is not as important as one would expect in the light of security concerns regarding online activity $[22,46]$. 
To ensure the development of secure location-based games, there should be more emphasis on security and privacy in the development process.

The aspect that scored the lowest was organisational structure. This might be due to the fact that games developers still try to be solo developers or lone wolf developers, as was the case at the inception of game development [24].

The average score of $73.3 \%$ ( 7.33 out of 10 ) for all the aspects indicates that the games developers on average agreed that the aspects identified were important for the development of location-based games.

In addition to the average, the median, minimum, maximum and standard deviation were also calculated to demonstrate the grouping of the data. Most of the aspects' standard deviations were between 1.77 and 2.73 with a total standard deviation for the entire dataset of 2.44. The ranking of the aspects seems to indicate that the games developers agree with the identified aspects.

Table 2. Frequency analysis

\begin{tabular}{ccccccccccc}
\hline & \multicolumn{1}{c}{ Ranking } \\
& 1 & 2 & 3 & 4 & 5 & 6 & 7 & 8 & 9 & 10 \\
\hline Playability & 0 & 0 & 1 & 4 & 3 & 0 & 2 & 9 & 17 & 42 \\
Player Experience & 1 & 0 & 0 & 3 & 4 & 2 & 3 & 10 & 12 & 43 \\
Usability & 0 & 0 & 3 & 3 & 2 & 6 & 10 & 21 & 10 & 23 \\
Value to the Player & 1 & 3 & 3 & 3 & 5 & 6 & 5 & 17 & 9 & 26 \\
User Interface Design & 0 & 2 & 2 & 4 & 6 & 7 & 16 & 13 & 10 & 18 \\
Development Team & 2 & 1 & 2 & 4 & 6 & 7 & 14 & 13 & 8 & 21 \\
Re-Playability & 2 & 2 & 4 & 3 & 6 & 10 & 6 & 12 & 15 & 18 \\
Learnability & 1 & 3 & 2 & 3 & 8 & 9 & 14 & 12 & 8 & 18 \\
Efficiency & 1 & 2 & 6 & 4 & 6 & 11 & 6 & 14 & 10 & 18 \\
Security and Privacy & 3 & 2 & 3 & 7 & 7 & 5 & 8 & 9 & 11 & 23 \\
Availability and Accessibility & 1 & 4 & 3 & 4 & 9 & 11 & 12 & 4 & 7 & 23 \\
Cognitive Support & 1 & 1 & 3 & 7 & 8 & 9 & 15 & 15 & 5 & 14 \\
Compatibility & 3 & 5 & 4 & 5 & 14 & 4 & 8 & 12 & 7 & 16 \\
Adaptability & 3 & 2 & 6 & 7 & 11 & 7 & 16 & 8 & 4 & 14 \\
Organisational Structure & 5 & 2 & 4 & 5 & 15 & 10 & 12 & 7 & 6 & 12 \\
\hline
\end{tabular}

The distribution of the rankings across the different aspects is shown in Table 2. The frequency indicates the number of times that a rank was assigned by the participants for that aspect. Ranking 10 with a frequency of 42 for playability shows that 42 of the 78 participants ranked playability's importance as 10 out of 10 .

The aspects that have been identified were matched to the responses given to the open-ended question to determine whether any aspects were overlooked in the literature search and to add any such aspects, however, all of the suggestions that the games developers made were either included in the list or was not deemed to be an aspect of location-based games. 


\section{Conclusions and Future Work}

In this study aspects that need to be addressed during the development of location-based games were identified from the literature. The aspects were then validated using an online survey to gather information from the gaming industry to determine how important each aspect is. Furthermore, this survey also gave the participants the ability to add aspects if any were neglected.

It was also noted that security and privacy was not regarded as one of the most important aspects needed in the development process of location-bases games. This is troubling as it leaves the players with a big security gap.

The results of this study can now be used to develop a framework that can be used to evaluate the suitability of different SDMs for the development of location-based games [4].

\section{References}

1. Al Bar, A., Mohamed, E., Akhtar, M.K., Abuhashish, F.: A preliminary review of implementing enterprise mobile application in ERP environment. International Journal of Engineering \& Technology 11(4), 77-82 (2011)

2. Ali, N., Ramos, I., Sols, C.: Ambient-PRISMA: Ambients in mobile aspect-oriented software architecture. Journal of Systems and Software 83(6), 937 - 958 (2010)

3. Bach, L., Cohendet, P., Pénin, J., Simon, L.: Creative industries and the IPR dilemma between appropriation and creation: some insights from the videogame and music industries. Management International 14(3), 59-72 (2010)

4. Barnard, J., Drevin, G., Huisman, M.: A Framework to Determine the Suitability of Software Development Methodologies for the Development of Location-Based Games. In: Munekata, N., Kunita, I., Hoshino, J. (eds.) 16th International Conference on Entertainment Computing ICEC 2017. Lecture Notes in Computer Science, vol. LNCS-10507, pp. 335-342. Springer International Publishing (Sep 2017)

5. Benbunan-Fich, R., Benbunan, A.: Understanding user behavior with new mobile applications. The Journal of Strategic Information Systems 16(4), 393 - 412 (2007)

6. Blow, J.: Game development: Harder than you think. Queue 1(10), 28-37 (Feb 2004)

7. Buzeto, F.N., e Silva, T.B.P., Castanho, C.D., Jacobi, R.P.: Reconfigurable games: Games that change with the environment. In: 2014 Brazilian Symposium on Computer Games and Digital Entertainment. pp. 61-70 (Nov 2014)

8. Callele, D., Neufeld, E., Schneider, K.: Requirements engineering and the creative process in the video game industry. In: Proceedings of the 13th IEEE International Conference on Requirements Engineering. pp. 240-252. RE '05 (2005)

9. Cohendet, P., Simon, L.: Playing across the playground: paradoxes of knowledge creation in the videogame firm. Journal of Organizational Behavior 28(5), 587-605 (2007)

10. Desurvire, H., Caplan, M., Toth, J.A.: Using heuristics to evaluate the playability of games. In: CHI '04 Extended Abstracts on Human Factors in Computing Systems. pp. 1509-1512. CHI EA '04 (2004)

11. Duarte, C., Afonso, A.P.: Developing once, deploying everywhere: A case study using JIL. Procedia Computer Science 5, 641 - 644 (2011) 
12. Federoff, M.A.: Heuristics and usability guidelines for the creation and evaluation of fun in video games. Master's thesis, Indiana University (2002)

13. Feijoo, C., Gómez-Barroso, J.L., Aguado, J.M., Ramos, S.: Mobile gaming: Industry challenges and policy implications. Telecommunications Policy 36(3), 212-221 (Apr 2012)

14. Frattesi, T., Griesbach, D., Leith, J., Shaffer, T., DeWinter, J.: Replayability of video games. IQP, Worcester Polytechnic Institute, Worcester (2011)

15. gamesindustry.biz: Game software market to hit $\$ 100$ billion by 2018 (June 2014), http://www.dfcint.com/wp/worldwide-market-forecasts-for-the-video-game-andinteractive-entertainment-industry/

16. González-Sánchez, J.L., Gutiérrez-Vela, F.L., Simarro, F.M., Padilla-Zea, N.: Playability: analysing user experience in video games. Behaviour \& Information Technology 31(10), 1033-1054 (2012)

17. Hagen, U.: Designing for player experience: How professional game developers communicate design visions. Journal of Gaming \& Virtual Worlds 3(3), 259-275 (2011)

18. Hansen, D., Bonsignore, E., Ruppel, M., Visconti, A., Kraus, K.: Designing reusable alternate reality games. In: Proceedings of the SIGCHI Conference on Human Factors in Computing Systems. pp. 1529-1538. CHI '13 (2013)

19. Heo, J., Ham, D.H., Park, S., Song, C., Yoon, W.C.: A framework for evaluating the usability of mobile phones based on multi-level, hierarchical model of usability factors. Interacting with Computers 21(4), 263 - 275 (2009)

20. Holzer, A., Ondrus, J.: Mobile application market: A developer's perspective. Telematics and Informatics 28(1), $22-31$ (2011)

21. Intelligence, D.: Worldwide market forecasts for the video game and interactive entertainment industry (2014), http://www.dfcint.com/wp/?p=48

22. Jain, A.K., Shanbhag, D.: Addressing security and privacy risks in mobile applications. IT Professional 14, 28-33 (09 2012)

23. Kao, Y.W., Lin, C., Yang, K.A., Yuan, S.M.: A web-based, offline-able, and personalized runtime environment for executing applications on mobile devices. Computer Standards \& Interfaces 34(1), 212 - 224 (2012)

24. Keith, C.: Agile game development with Scrum. Pearson Education (2010)

25. Kim, H., Choi, B., Wong, W.E.: Performance testing of mobile applications at the unit test level. In: 2009 Third IEEE International Conference on Secure Software Integration and Reliability Improvement. pp. 171-180 (July 2009)

26. Korhonen, H., Koivisto, E.M.I.: Playability heuristics for mobile games. In: Proceedings of the 8th Conference on Human-Computer Interaction with Mobile Devices and Services. pp. 9-16. MobileHCI '06 (2006)

27. Korhonen, H., Koivisto, E.M.I.: Playability heuristics for mobile multi-player games. In: Proceedings of the 2nd International Conference on Digital Interactive Media in Entertainment and Arts. pp. 28-35. DIMEA '07 (2007)

28. Krall, J., Menzies, T.: Aspects of replayability and software engineering: Towards a methodology of developing games. Journal of Software Engineering and Applications 5(7), 459-466 (2012)

29. Lukashev, D., Puresev, A., Makhlushev, I.: 3D applications for 3G mobile phones: Design, development, resource utilization. In: 2006 IEEE International Symposium on Consumer Electronics. pp. 1-4 (2006)

30. Nacke, L.E., Drachen, A., Göbel, S.: Methods for evaluating gameplay experience in a serious gaming context. International Journal of Computer Science in Sport $\mathbf{9}(2), 1-12(2010)$ 
31. Nacke, L., Drachen, A.: Towards a framework of player experience research. In: Proceedings of the Second International Workshop on Evaluating Player Experience in Games at FDG. vol. 11 (2011)

32. Nacke, L.E., Drachen, A., Kuikkaniemi, K., Niesenhaus, J., Korhonen, H., van den Hoogen, W.M., Poels, K., IJsselsteijn, W.A., de Kort, Y.A.W.: Playability and player experience research [panel abstracts]. In: DiGRA '09 - Proceedings of the 2009 DiGRA International Conference: Breaking New Ground: Innovation in Games, Play, Practice and Theory. Brunel University (September 2009)

33. Novak, J.: Game development essentials: an introduction. Cengage Learning (2011)

34. Padilla-Zea, N., López-Arcos, J.R., Sánchez, J.L.G., Vela, F.L.G., Abad-Arranz, A.: A method to evaluate emotions in educational video games for children. Journal of Universal Computer Science 19(8), 1066-1085 (2013)

35. Plaza, I., Martín, L., Martin, S., Medrano, C.: Mobile applications in an aging society: Status and trends. Journal of Systems and Software 84(11), 1977 - 1988 (2011)

36. Puttaswamy, K.P.N., Wang, S., Steinbauer, T., Agrawal, D., E., A.A., Kruegel, C., Zhao, B.Y.: Preserving location privacy in geosocial applications. IEEE Transactions on Mobile Computing 13(1), 159-173 (Jan 2014)

37. Reyno, E.M., Carsí Cubel, J.A.: Model-driven game development: 2D platform game prototyping. In: Proceedings of the 13th IEEE International Conference on Requirements Engineering. pp. 5-7. GAMEON'2008 (2008)

38. Rice, R.E., Katz, J.E.: Assessing new cell phone text and video services. Telecommunications Policy 32(7), 455-467 (2008)

39. Ryan, W., Siegel, M.A.: Evaluating interactive entertainment using breakdown: Understanding embodied learning in video games. In: Proceedings of DiGRA (2009)

40. Scipioni, M.P., Langheinrich, M.: I'm here! privacy challenges in mobile location sharing. In: Second International Workshop on Security and Privacy in Spontaneous Interaction and Mobile Phone Use (IWSSI/SPMU) (2010)

41. Tschang, F.T.: Balancing the tensions between rationalization and creativity in the video games industry. Organization Science 18(6), 989-1005 (2007)

42. Unhelkar, B., Murugesan, S.: The enterprise mobile applications development framework. IT Professional 12(3), 33-39 (May 2010)

43. Verkasalo, H.: From intentions to active usage: a study on mobile services in Finland. In: 19th European regional ITS conference. Rome. pp. 18-20 (2008)

44. Verkasalo, H., López-Nicolás, C., Molina-Castillo, F.J., Bouwman, H.: Analysis of users and non-users of smartphone applications. Telematics and Informatics 27(3), 242-255 (2010)

45. Viana, W., Andrade, R.M.: XMobile: A MB-UID environment for semi-automatic generation of adaptive applications for mobile devices. Journal of Systems and Software 81(3), $382-394$ (2008)

46. Zhu, H., Xiong, H., Ge, Y., Chen, E.: Mobile app recommendations with security and privacy awareness. In: Proceedings of the 20th ACM SIGKDD International Conference on Knowledge Discovery and Data Mining. pp. 951-960. KDD '14 (2014) 